\title{
Acquired Angioedema with C1 Inhibitor Deficiency: Occurrence, Clinical Features, and Management: A Nationwide Retrospective Study in the Czech Republic Patients
}

\author{
Marta Sobotkova $^{a}$ Radana Zachova $^{a}$ Roman Hakl $^{\mathrm{b}}$ Pavel Kuklinek ${ }^{\mathrm{b}}$ \\ Pavlina Kralickova ${ }^{c}$ Irena Krcmova ${ }^{c}$ Jana Hanzlikovad ${ }^{d}$ Martina Vachova ${ }^{d}$ \\ Jirina Bartunkova ${ }^{a}$ \\ aDepartment of Immunology, 2nd Faculty of Medicine Charles University and Motol University Hospital, Prague, \\ Czech Republic; ' Department of Clinical Immunology and Allergology, St Anne's University Hospital in Brno, Faculty \\ of Medicine Masaryk University, Brno, Czech Republic; 'Institute of Clinical Immunology and Allergy, University \\ Hospital Hradec Kralove, Faculty of Medicine, Charles University, Hradec Kralove, Czech Republic; ${ }^{\mathrm{d} D e p a r t m e n t}$ of \\ Immunology and Allergology, University Hospital and Faculty of Medicine in Pilsen, Pilsen, Czech Republic
}

\section{Keywords}

Acquired angioedema · C1 inhibitor · Bradykinin ·

Lymphoma

\begin{abstract}
Introduction: Acquired angioedema with $\mathrm{C} 1$ inhibitor deficiency (AAE-C1-INH) is rare but a potentially life-threatening disease. There are no official prevalence data, nor approved therapies for this condition. Objective: In this study, we aimed to collect and analyze clinical data on patients with AAE-C1-INH in the Czech Republic. Methods: We have conducted a retrospective analysis of $A A E-C 1-I N H$ patients from Czech referral centers for the treatment of hereditary angioedema with $\mathrm{C} 1$ inhibitor deficiency. The inclusion criteria involved recurrent episodes of angioedema with the first manifestation at or after the age of 40 , negative family history of angioedema, and C1 inhibitor function $50 \%$ or less. Results: A total of 14 patients ( 7 males and 7 females) met the inclusion criteria for AAE-C1-INH. The median age of the symptom onset was 59.5 years, and the median diagnosis delay was 1 year. The most common clinical manifestation was facial
\end{abstract}

karger@karger.com www.karger.com/iaa

Karger!"

GOPEN ACCESS
(C) 2021 The Author(s)

Published by S. Karger AG, Basel

This is an Open Access article licensed under the Creative Commons Attribution-NonCommercial-4.0 International License (CC BY-NC) (http://www.karger.com/Services/OpenAccessLicense), applicable to the online version of the article only. Usage and distribution for commercial purposes requires written permission. edema (100\%) and upper airway swelling (85.7\%). All patients responded to the acute attack treatment with icatibant and plasma-derived or recombinant C1 inhibitor concentrate. Lymphoid malignancy was identified in 9 patients (64\%), monoclonal gammopathy of uncertain significance in $3(21 \%)$, and in 1 patient autoimmune disease (ulcerative colitis) was considered causative (7\%). We were not able to identify any underlying disease only in 1 patient (7\%). In 6 of 7 patients (86\%) treated for lymphoma, either a reduction in the frequency of angioedema attacks or both angioedema symptoms' disappearance and complement parameter normalization was observed. Conclusions: The prevalence of AAE-C1-INH in the Czech Republic is about $1: 760,000$. This rare condition occurs in approximately $8 \%$ of the patients with angioedema with $\mathrm{C} 1$ inhibitor deficiency. AAE-C1-INH is strongly associated with lymphoproliferative disorders, and treating these conditions may improve the control of angioedema symptoms.

(C) 2021 The Author(s).

Published by S. Karger AG, Basel

Edited by: H.-U. Simon, Bern.
Marta Sobotkova

Department of Immunology, 2nd Faculty of Medicine, Charles University and Motol University Hospital, V Úvalu 84

CZ-150 06 Prague (Czechia),

marta.sobotkova@fnmotol.cz 


\section{Introduction}

Acquired angioedema with $\mathrm{C} 1$ inhibitor deficiency (AAE-C1-INH) is a rare condition with similar clinical features as the hereditary $\mathrm{C} 1$ inhibitor $(\mathrm{C} 1-\mathrm{INH})$ deficiency [1]. Patients with AAE-C1-INH experience episodes of angioedema located in various body locations, including the airways. Therefore, it is a potentially lifethreatening disease [2-4]. Angioedema formation is mediated by bradykinin (BK), which is the end product of kallikrein-kinin system. Because of the C1-INH deficien$\mathrm{cy}$, the uncontrolled activation of this system prevails and further leads to the excessive production of $\mathrm{BK}[1,3]$.

Hereditary angioedema with $\mathrm{C} 1$ inhibitor deficiency (HAE-C1-INH) is an autosomal dominant disease caused by mutations in the SERPING1 gene. These mutations can result in a decreased production of $\mathrm{C} 1-\mathrm{INH}$, thus resulting in low quantitative levels of C1-INH in patient's plasma. However, the mutations may also generate dysfunctional C1-INH protein, which is accompanied by normal or increased C1-INH plasma levels $[3,5,6]$. In AAE-C1-INH, the exact pathogenesis of C1-INH deficiency has not been fully elucidated yet $[5,7,8]$. Nevertheless, different theories have been proposed. One of the theories suggests that a pathological B-cell proliferation may result in the expansion of B cells capable of producing neutralizing antibodies against $\mathrm{C} 1-\mathrm{INH}$. These antibodies were previously detected in about $70 \%$ of patients with AAE-C1-INH [5, 7-9]. Another theory considers a massive activation of the classical complement pathway by the tumor tissue or by abnormal antibodies resulting in a subsequent consumption of $\mathrm{C} 1$-INH $[5,7,8]$.

AAE-C1-INH is frequently associated with lymphoproliferative disorders, such as NHL or monoclonal gammopathy of undetermined significance (MGUS) $[2,7,8]$. Other cases of AAE-C1-INH may accompany various malignancies, as well as autoimmune diseases. In a small number of patients, associated disorders cannot be found $[3,5,8]$.

The diagnosis is based on the history of recurrent angioedema, missing family history of angioedema, and C1INH functional levels below $50 \%[3,8]$. The onset of symptoms is late (usually after 40 years of age). C1-INH deficiency is usually accompanied by low $\mathrm{C} 4, \mathrm{C} 1 \mathrm{q}$, and $\mathrm{CH} 50$ levels and by the presence of anti-C1-INH antibodies $[3,5,8,10]$.

The treatment of AAE-C1-INH consists of management of both the angioedema attacks and the underlying disease. Similar drugs recommended for treatment of HAE-C1-INH can be administered for angioedema treatment in AAE-C1-INH. However, all of these agents are used off-label [2,3]. C1-INH concentrate, human plasma, icatibant, or ecallantide can be used for the acute attack treatment $[2,3,5,11,12]$. Tranexamic acid (TA) or danazol was mostly used for prevention of angioedema attacks in AAE-C1-INH patient cohorts published so far [3, $4,7,10]$. In some cases, regular C1-INH concentrate administration may also be recommended for long-term prophylaxis (LTP) [2]. Some therapeutic approaches, such as angiotensin-converting enzyme inhibitors (ACEI) or estrogen agents, may worsen angioedema symptoms, and therefore, patients with C1-INH deficiency should avoid them. Treatment of the underlying disease depends on the specific diagnosis. However, in the treatment of C1-INH deficiency, rituximab alone or in a combination with chemotherapy is generally recommended for the treatment of lymphoproliferative disorders $[3,11,12]$.

Precise epidemiological data about AAE-C1-INH are not known, but estimated prevalence ranges between 1:100,000 and 1:500,000 $[2,5]$. Since our knowledge about AAE-C1INH is still limited, the purpose of our study is to bring more data about this rare condition. We have retrospectively collected available data on AAE-C1-INH patients in the Czech Republic and evaluated the disease manifestation, associated conditions, and the response to the treatment.

\section{Materials and Methods}

In April 2019, all 4 referral centers for the treatment of HAE$\mathrm{C} 1-\mathrm{INH}$ in the Czech Republic were asked to retrospectively search their databases for patients meeting inclusion criteria. Specific treatment for BK-mediated angioedema is available only in these centers. It is, therefore, assumed that all the symptomatic Czech AAE-C1-INH patients under treatment were included.

Our inclusion criteria were as follows: patients with recurrent episodes of angioedema, which first manifested at the age of 40 or later, negative family history of angioedema, and C1-INH function $50 \%$ or less. Clinical data were collected from medical records and included gender, date of birth, age at the first manifestation of angioedema, date of diagnosis, laboratory characteristics (plasma levels of $\mathrm{C} 1-\mathrm{INH}, \mathrm{C} 4, \mathrm{C} 1 \mathrm{q}$, and $\mathrm{C} 1-\mathrm{INH}$ function), angioedema localization, response to acute attack and prophylactic treatment, and the information about the underlying disease. In cases where concomitant diseases were identified, we also monitored the response of AAE-C1-INH to the therapy.

Measurements of plasma levels of C4, C1-INH, C1q, and C1INH function were performed in local laboratories or cooperating laboratories of participating centers. As shown in Table 1, diverse laboratory methods were used. In all patients, the genetic analysis was performed at the Molecular Genetics Laboratory, Center for Cardiovascular Surgery and Transplantation in Brno. Sanger sequencing and multiplex ligation-dependent probe amplification was used for the purpose of genetic analyses. Since there is currently no laboratory in the Czech Republic for the anti-C1-INH antibody detection, this parameter is not available in our cohort. 
Table 1. List of laboratory methods used in participating centers and included patients

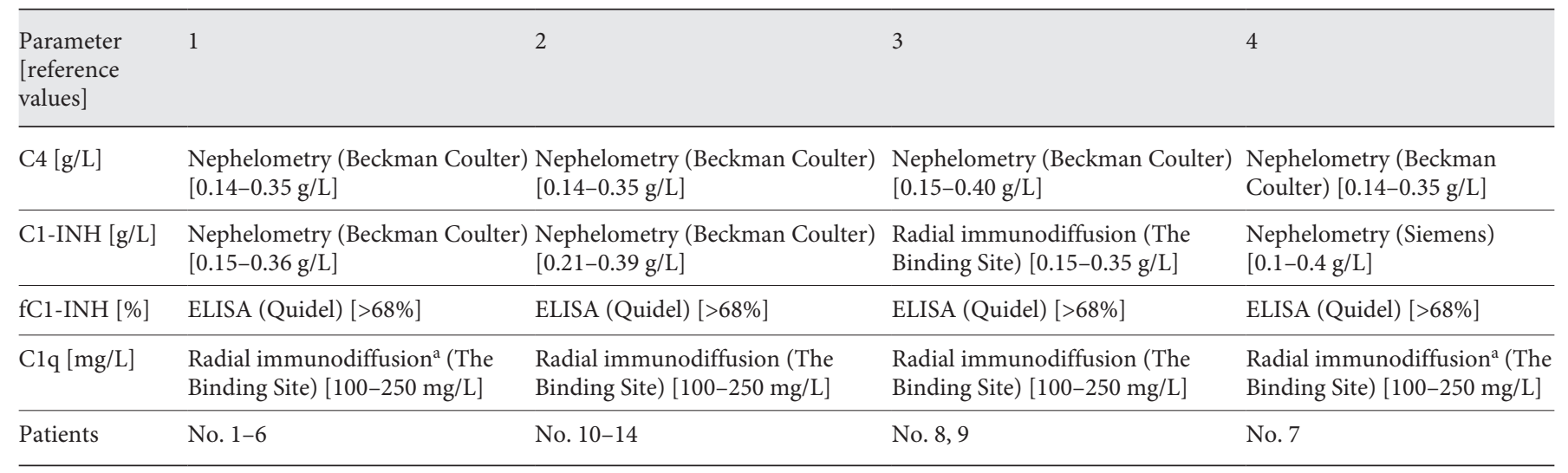

1 Department of Immunology, Second Faculty of Medicine, Charles University and Motol University Hospital (Prague). 2 Department of Clinical Immunology and Allergology, St Anne's University Hospital in Brno, Faculty of Medicine, Masaryk University (Brno). 3 Institute of Clinical Immunology and Allergy, University Hospital Hradec Kralove, Faculty of Medicine, Charles University (Hradec Kralove). 4 Department of Immunology and Allergology, University Hospital and Faculty of Medicine in Pilsen (Pilsen). C1-INH, C1 inhibitor; fC1-INH, C1 inhibitor function; ELISA, enzyme-linked immunosorbent

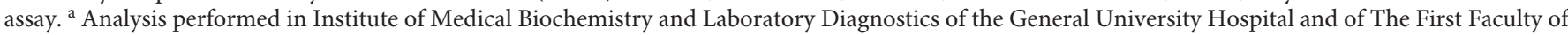
Medicine of Charles University (Prague).

Table 2. List of included patients - basic characteristics

\begin{tabular}{|c|c|c|c|c|c|c|c|c|c|c|c|}
\hline $\begin{array}{l}\text { Patient, } \\
n\end{array}$ & $\begin{array}{l}\text { Gender/ } \\
\text { age at first } \\
\text { swelling, } \\
\text { years }\end{array}$ & $\begin{array}{l}\text { Year of } \\
\text { diagnosis/ } \\
\text { diagnosis } \\
\text { delay, years }\end{array}$ & Facial & $\begin{array}{l}\text { Abdom- } \\
\text { inal }\end{array}$ & $\begin{array}{l}\text { Upper } \\
\text { airway } \\
\text { and } \\
\text { tongue }\end{array}$ & $\begin{array}{l}\text { Peri- } \\
\text { pheral }\end{array}$ & $\begin{array}{l}\text { C1-INH } \\
\text { antigen }(\mathrm{g} / \mathrm{L}) \\
{[0.15-0.39} \\
\mathrm{g} / \mathrm{L}]^{\mathrm{a}}\end{array}$ & $\begin{array}{l}\text { C1-INH } \\
\text { function } \\
(\%)[>68 \%]\end{array}$ & $\begin{array}{l}\text { C4 antigen } \\
(\mathrm{g} / \mathrm{L})[0.14- \\
0.40 \mathrm{~g} / \mathrm{L}]^{\mathrm{a}}\end{array}$ & $\begin{array}{l}\text { C1q antigen } \\
(\mathrm{mg} / \mathrm{L}) \\
{[100-250 \mathrm{mg} / \mathrm{L}]}\end{array}$ & $\begin{array}{l}\text { Family history/genetic } \\
\text { testing - SERPING1 } \\
\text { gene mutation }\end{array}$ \\
\hline 1 & $\mathrm{~F} / 58$ & $2013 / 2$ & $\mathrm{X}$ & $\mathrm{X}$ & $\mathrm{X}$ & $\mathrm{X}$ & $<0.05$ & 28 & 0.02 & $<12$ & Neg/neg \\
\hline 2 & $\mathrm{M} / 40$ & $2013 / 0$ & $\mathrm{X}$ & $\mathrm{X}$ & $\mathrm{X}$ & $\mathrm{X}$ & 0.04 & 0 & $<0.02$ & $<12$ & Neg/neg \\
\hline 4 & $\mathrm{~F} / 82$ & $2013 / 1$ & $\mathrm{X}$ & $\mathrm{X}$ & $\mathrm{X}$ & $\mathrm{X}$ & 0.1 & 4 & 0.04 & 86 & Neg/neg \\
\hline 5 & $\mathrm{~F} / 62$ & $2015 / 0$ & $\mathrm{X}$ & & $\mathrm{X}$ & & 0.1 & 31 & $<0.02$ & 137 & Neg/NA \\
\hline 6 & $\mathrm{~F} / 50$ & $2006 / 3$ & $\mathrm{X}$ & $\mathrm{X}$ & $\mathrm{X}$ & $\mathrm{X}$ & 0.05 & 38 & 0.02 & 142 & Neg/neg \\
\hline 7 & $\mathrm{M} / 63$ & $2012 / 1$ & $\mathrm{X}$ & & $\mathrm{X}$ & & 0.05 & 44 & $<0.06$ & $<12$ & Neg/neg \\
\hline 10 & $\mathrm{M} / 71$ & $2012 / 0$ & $\mathrm{X}$ & & $\mathrm{X}$ & & 0.08 & 41 & $<0.02$ & 90 & Neg/neg \\
\hline $11^{\mathrm{b}}$ & $\mathrm{F} / 64$ & $2012 / 3$ & $\mathrm{X}$ & $\mathrm{X}$ & $\mathrm{X}$ & $\mathrm{X}$ & 0.03 & 49 & $<0.02$ & 87 & Neg/neg \\
\hline $12^{\mathrm{b}}$ & $\mathrm{M} / 49$ & $2013 / 0$ & $\mathrm{X}$ & & $\mathrm{X}$ & & $<0.03$ & 9 & $<0.02$ & 29 & Neg/NA \\
\hline 13 & $\mathrm{M} / 61$ & $2007 / 3$ & $\mathrm{X}$ & & $\mathrm{X}$ & & $<0.03$ & 5 & $<0.02$ & UD & Neg/neg \\
\hline 14 & $\mathrm{M} / 40$ & $2008 / 0$ & $\mathrm{X}$ & & & $\mathrm{X}$ & 0.06 & 31 & 0.04 & 154 & Neg/neg \\
\hline
\end{tabular}

C1-INH, C1 inhibitor; F, female; M, male; neg, negative; NA, not available; UD, undetectable. ${ }^{\text {a }}$ Reference values may depend on the methods listed in Table $1 .{ }^{\mathrm{b}}$ Patient has died. 
Table 3. Angioedema treatment outcomes

\begin{tabular}{|c|c|c|c|c|c|c|c|}
\hline \multirow{2}{*}{$\begin{array}{l}\text { Patient, } \\
n\end{array}$} & \multicolumn{3}{|c|}{ Acute attack treatment } & \multicolumn{2}{|l|}{ Long-term prophylaxis } & \multirow{2}{*}{$\begin{array}{l}\text { Short-term prophylaxis } \\
\text { pdC1INH/treatment } \\
\text { effectivity }\end{array}$} & \multirow{2}{*}{$\begin{array}{l}\text { Treatment with ACEI } \\
\text { or estrogens before } \\
\text { diagnosis/effect of } \\
\text { discontinuation }\end{array}$} \\
\hline & icatibant & pdC1INH & rhC1INH & $\begin{array}{l}\text { danazol/treatment } \\
\text { effectivity }\end{array}$ & $\begin{array}{l}\text { tranexamic acid/ } \\
\text { treatment effectivity }\end{array}$ & & \\
\hline 1 & $\mathrm{E}$ & - & $\mathrm{E}$ & $100 \mathrm{mg}$ daily/E & - & - & - \\
\hline 2 & $\mathrm{E}$ & - & - & - & - & $1,000 \mathrm{IU} / \mathrm{E}$ & - \\
\hline 3 & - & - & - & - & 250-750 mg daily/E & - & $\mathrm{ACEI} / \mathrm{E}$ \\
\hline 4 & $\mathrm{E}$ & - & $\mathrm{E}$ & - & 500-1,000 mg daily/E & - & - \\
\hline 5 & - & - & - & - & - & - & ACEI/NE \\
\hline 6 & $\mathrm{E}$ & $\mathrm{E}$ & $\mathrm{E}$ & 200 mg daily/E & $1 \mathrm{~g}$ daily/NE & 0 & $\mathrm{ACEI} / \mathrm{NE}$ \\
\hline 7 & $\mathrm{E}$ & $\mathrm{E}$ & - & - & $500 \mathrm{mg}$ daily/E & - & - \\
\hline 8 & - & - & - & - & $1 \mathrm{~g}$ daily/E & - & $\mathrm{ACEI} / \mathrm{E}$ \\
\hline 9 & $\mathrm{E}$ & $\mathrm{E}$ & - & - & - & $1,000 \mathrm{IU} / \mathrm{E}$ & - \\
\hline 10 & - & - & - & $100 \mathrm{mg}$ every other day/E & - & $1,000 \mathrm{IU} / \mathrm{E}$ & $\mathrm{ACEI} / \mathrm{E}$ \\
\hline 11 & $\mathrm{E}$ & - & - & - & - & - & - \\
\hline 12 & - & - & - & - & - & - & - \\
\hline 13 & $\mathrm{E}$ & $\mathrm{E}$ & - & 200 mg daily/E & - & $1,000 \mathrm{IU} / \mathrm{E}$ & $\mathrm{ACEI} / \mathrm{E}^{\mathrm{a}}$ \\
\hline 14 & - & - & $\mathrm{E}$ & $200 \mathrm{mg}$ daily/E & - & - & - \\
\hline
\end{tabular}

Treatment for acute attack was considered effective if angioedema resolved in $24 \mathrm{~h}$ after administration. Prophylactic treatment with tranexamic acid or attenuated androgens (danazol) and effect of discontinuation of ACEI or estrogens were considered efficient if we recorded at least $50 \%$ attack rate reduction compared to the 6-month period before prophylaxis was introduced. Short-term prophylaxis was considered efficient if no edema occurred $48 \mathrm{~h}$ after surgery (or other intervention). ACEI, angiotensin-converting-enzyme inhibitors; pdC1INH, plasma-derived C1 inhibitor concentrate; rhC1INH, recombinant C1-INH concentrate; E, effective; NE, not effective. ${ }^{a} \mathrm{ACEI}$, introduced in 2015 resulting in 3 attacks per month, on discontinuation reduced symptoms.

\section{Results}

Participating centers identified 14 patients meeting the inclusion criteria. The female: male ratio was $1: 1$ (Table 2). Age at the first symptoms ranged from 40 to 82 (median age 59.5 years), and diagnosis delay ranged from 0 to 15 years (median delay 1 year). The most common manifestation was facial edema (14 of $14 ; 100 \%$ ), followed by the upper airway involvement (12 of 14; $85.7 \%$ ), abdominal attacks ( 7 of $14 ; 50 \%$ ), and peripheral angioedema (6 of 14; 42.8\%). C4 antigen level and C1-INH function were below the reference range in all cases $(14$ of $14 ; 100 \%)$. Low C1-INH antigen level was detected in all patients except for one (13 of 14; 93\%), and low $\mathrm{C} 1 \mathrm{q}$ antigen level was found in 10 patients (10 of $14 ; 71.4 \%)$. The patients were observed for $1-13$ years with a median follow-up of 6 years since the diagnosis of AAE-C1-INH. In our study cohort, 1 patient (No. 11) died of leukemia and 1 patient (No. 12) died of nonHodgkin lymphoma.

The efficacy of angioedema treatment was also evaluated in our patients (Table 3 ). Nine patients ( 9 of 14;64\%) required acute attack treatment. In 8 patients with acute attack treatment, icatibant was administered $(n=8)$, plasma-derived C1-INH concentrate (pdC1INH; Berinert ${ }^{\circledR}$ ) was used in 4 cases $(n=4)$, and 4 patients $(n=4)$ received recombinant $\mathrm{C} 1$-INH concentrate. All drugs were found to be efficient in all cases.

LTP was initiated in 9 patients ( 9 of $14 ; 64 \%$ ). TA was used in 5 patients $(n=5)$. In 2 patients $(2$ of $5 ; 40 \%)$, where TA was administered as a single agent, the treatment was assessed as potent and efficient. Three patients ( 3 of 5; 60\%) started TA therapy while discontinuing ACEI treatment. The favorable response was observed in 2 of these 3 patients. Nevertheless, the nonresponder ( 1 out of 3 patients) exhibited a rapid response to danazol. In 5 patients ( 5 of 9 ; 
Table 4. Associated conditions and treatment effectiveness on AAE

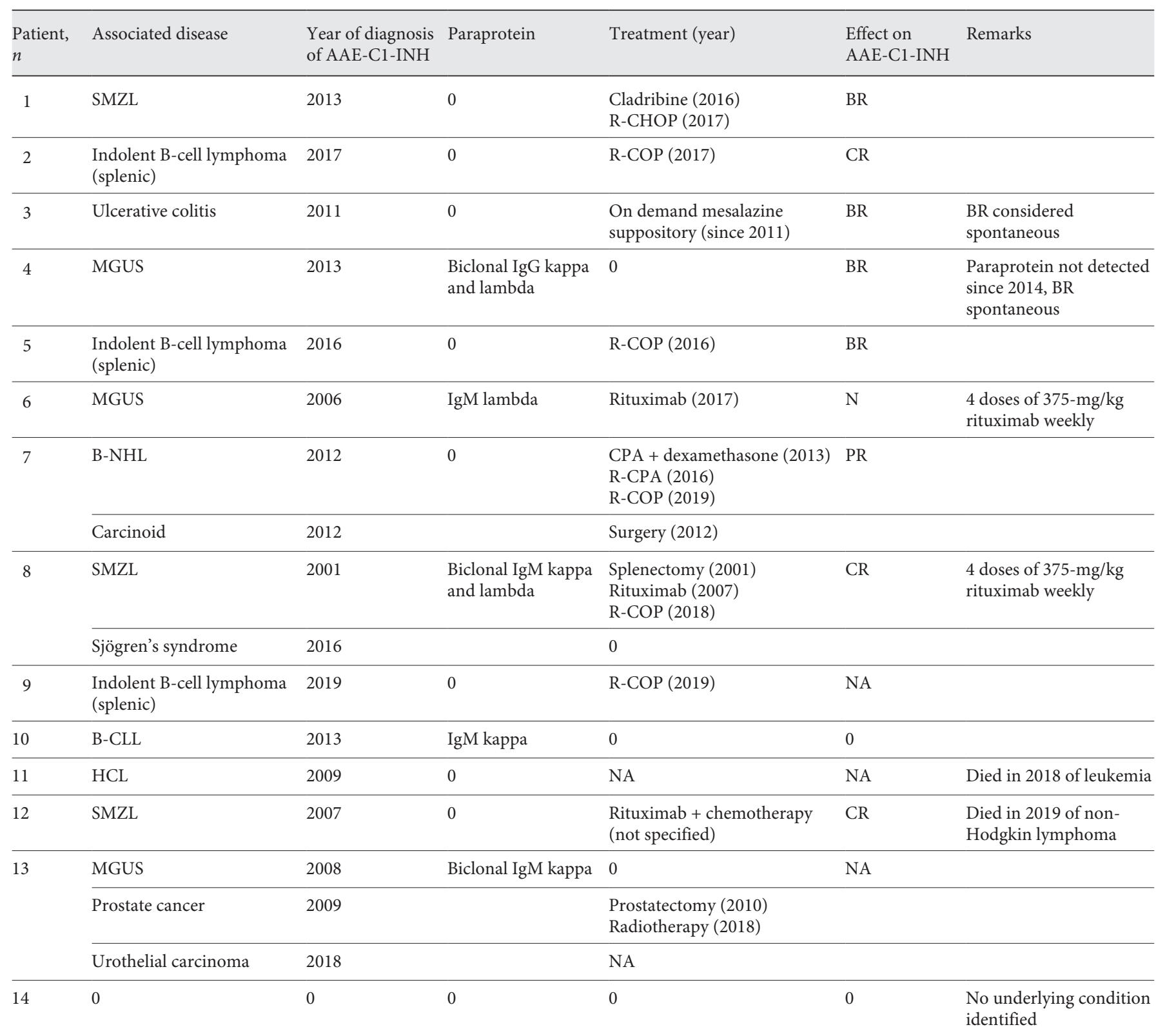

Effect of underlying disease treatment on angioedema was evaluated as partial remission (PR) if number of attacks after treatment reduced at least to $50 \%$ compared to 6-month period before treatment, but C1-INH deficiency was still present; complete remission (CR) if patients experienced no further attacks after the treatment, but C1-INH deficiency was still present; biological remission (BR) if there were no attacks after treatment and C1-INH deficiency resolved; progression $(\mathrm{P})$ if number of attacks increased for $50 \%$ or more compared to 6-month period before treatment or state not changed $(\mathrm{N})$ if patient met no criteria mentioned before. If patient was not treated, 0 is listed. AAE-C1-INH, acquired angioedema with C1 inhibitor deficiency; B-CLL, B-cell chronic lymphocytic leukemia; B-NHL, B-cell non-Hodgkin lymphoma; CPA, cyclophosphamide; HCL, hairy cell leukemia; MGUS, monoclonal gammopathy; NA, data not available; R-CHOP, rituximab, cyclophosphamide, vincristine, doxorubicin, prednisone; R-COP, rituximab, cyclophosphamide, vincristine, prednisone; R-CPA, rituximab, cyclophosphamide; SMZL, splenic marginal zone lymphoma.

55\%), danazol was administered as prophylaxis, and the drug was found to be efficient in $100 \%$ of the cases. In 1 patient, ACEI was withdrawn together with danazol treatment. In 1 patient (No. 5), the discontinuation of ACEI was the only therapeutic action, however, did not affect the attack frequency. In 1 patient (No. 14), ACEI was introduced during the observation period by a general practitioner resulting in frequent angioedema attacks (3 per month). Situ- 
ation stabilized after the discontinuation of ACEI. Shortterm prophylaxis with pdC1INH was used in 4 patients $(n=4)$, and in all cases, patients did not develop any swelling within the 48-h period postintervention.

Since AAE-C1-INH is usually associated with other conditions, we have also tried to identify underlying disease (Table 4). In 13 patients (13 of 14; 93\%), at least one potentially underlying health condition was identified. Only in 1 patient ( 1 of $14 ; 7 \%$ ), we were not able to identify any malignancy, lymphoproliferative disorder, or autoimmune disease. Lymphoid malignancy was identified in 9 patients ( 9 of $14 ; 64 \%$ ). The most prevalent malignancies were splenic marginal zone lymphoma (SMZL; $n=3$ ) and indolent B-cell lymphoma with splenomegaly $(n=3)$, followed by a B-cell NHL $(n=1)$, hairy cell leukemia $(n=$ $1)$, and chronic lymphocytic leukemia $(n=1)$. MGUS was diagnosed in 3 patients ( 3 of $14 ; 21 \%$ ).

Only 2 patients were diagnosed with autoimmunity. One patient was already treated for ulcerative colitis (No. 3), and the other one developed Sjögren's syndrome during the follow-up period (No. 8). Tumor duplicity was detected in 1 patient (No. 7) with the diagnosis of B-NHL and carcinoid. Tumor duplicity occurred also in patient No. 13 with MGUS, who developed prostate cancer and urothelial carcinoma during the follow-up period. In patients with lymphoid malignancy, $7(n=7)$ received oncologic treatment. We observed normalizing complement parameters together with complete angioedema symptom disappearance in 2 of them ( 2 of $7,28.5 \%)$. One of these patients (No. 5) did not receive any LTP, and the second one (No. 1) was treated with danazol. In the patient with danazol LTP, the disease remission was seen even after the end of LTP. Three patients were symptom-free after the lymphoid malignancy treatment, but the C1-INH deficiency was still present ( 3 of 7; 43\%). Out of these patients, 2 (No. 5 and No. 12) had no LTP and one (No. 8) was treated with TA. In 1 patient (No. 7; 1 out of 7, 14\%), the treatment of lymphoma led to the reduction of angioedema symptoms. However, the effect was surely affected by TA treatment. One patient (No. 9) was enrolled in our study shortly after the initiation of the SMZL treatment. Thus, we did not have any treatment outcomes yet. One severe AAE-C1-INH patient with MGUS was treated with rituximab (No. 6), but this treatment did not affect angioedema symptoms. In 1 MGUS patient (No.4), paraprotein disappeared during the follow-up period, and this was followed by the normalization of complement parameters. The patient did not experience any episode of angioedema after the danazol LTP discontinuation. Spontaneous AAE remission was also observed in a patient with ulcerative colitis (No. 3).

Acquired Angioedema with C1 Inhibitor

Deficiency: Czech Republic Results

\section{Discussion}

This is the first study in the Czech Republic evaluating patients with AAE-C1-INH. We found 14 patients who met the inclusion criteria. All of them were alive in 2018 when the Czech Republic had 10,650 000 inhabitants [13]. The counted prevalence of AAE-C1-INH in the year 2018 is, therefore, $1: 760,714$. This prevalence lower than the estimated 1:500,000-1:100,000 may be due to a proportion of undiagnosed patients. Nevertheless, the disease prevalence in the Czech Republic might be indeed lower than estimated $[2,5]$. There were 161 patients with HAE-C1-INH listed in the National Primary Immunodeficiency Database in the year 2018. Thus, the ratio of AAE-C1-INH to HAE-C1-INH patients is 1:11.5. This number is higher than that in the Danish cohort (1:13) but lower than that in the Italian cohort $(1: 8.8)[4,10]$.

The median diagnosis delay in our patients was 1 year. Since the median delay for diagnosis of HAE-C1-INH in Europe is $>8.5$ years, AAE-C1-INH in our patients was diagnosed much faster [14]. Since earlier onset of symptoms in HAE patients correlates with longer diagnosis delay, faster diagnosis in AAE-C1-INH patients could be explained by later onset of angioedema symptoms [15]. As compared to the other European AAE-C1-INH cohorts, we obtained a similar median delay to French cohorts (10 months) and Italian cohorts (2 years) $[3,10]$. The longest diagnosis delay in our cohort was 15 years (patient No. 8). This patient experienced first angioedema attack in 2001, but it was followed by long asymptomatic period until 2016, when second attack occurred. Diagnosis of AAE-C1-INH was established right after this second attack.

In all of our patients, the serum level of $\mathrm{C} 4$ was remarkably low together with low C1-INH function and, therefore, represented a useful screening tool for C1-INH deficiency. Although AAE-C1-INH should be considered mostly in patients with C1-INH deficiency and angioedema symptoms onset after 40 years of age, the median age of disease onset in our patients was 59.5 years. Our findings correlated with the largest cohort of 92 AAE-C1INH patients described in France, where AAE occurred primarily in the sixth decade of age (median onset, 62 years) [3].

All patients experienced facial edema, and $>85 \%$ of the patients also experienced edema of the upper respiratory tract. These data are similar to those of the Danish cohort, where upper airway involvement was the most common manifestation followed by facial edema. In the French/

Int Arch Allergy Immunol 2021;182:642-649 647 
Italian cohorts, facial and abdominal attacks were the most frequent events $[3,4,10]$.

All patients responded favorably to acute attack treatment available for HAE-C1-INH. Since only the treatment for facial, abdominal, and laryngeal attacks is covered by insurance, no other attacks were treated in our cohort. LTP was initiated in 9 patients. In 5 patients ( 5 of 9), TA was administered. Four of them (4 of 5) responded satisfyingly. Five patients ( 5 of 9 ) were treated with danazol, and in all of them (5 of 5), we observed symptom reduction. However, our group is rather small and quite heterogenic (some patients also stopped ACEI together with LTP introduction, patients had a different underlying disease and some of them were treated for it, etc.). Therefore, we were not able to evaluate the superiority of one particular treatment over the other.

In accordance with the previous European studies, the most commonly identified underlying disease was B-cell lymphoid malignancy, mostly SMZL or indolent B-cell lymphoma with splenomegaly. The second most common underlying condition was MGUS. One patient had only a transient MGUS, and after the paraprotein disappearance, C1-INH deficiency resolved too. Autoimmunity alone, specifically ulcerative colitis, was found only in 1 patient, but in this patient, C1-INH deficiency was resolved spontaneously after 3 years. Sjögren's syndrome was another identified autoimmunity in our cohort. The patient, however, developed Sjögren's syndrome 15 years after the diagnosis and treatment of SMZL and remained angioedema-free for 15 years. Therefore, we do not consider this condition as causative for $\mathrm{C} 1-\mathrm{INH}$ deficiency.

We have observed a favorable effect of lymphoma treatment on AAE-C1-INH in 6 of $7(86 \%)$ treated patients, and in 4 of them ( 4 of $6 ; 67 \%$ ), this effect was not influenced by LTP. In a patient treated with rituximab for MGUS, angioedema frequency was not affected. With regard to these findings, we can recommend taking AAEC1-INH into account when lymphoma treatment is considered. As compared to the French cohort, where 2 patients with MGUS-associated AAE responded favorably to the treatment, we did not find rituximab effective in our patient.

\section{Conclusion}

Our study confirms AAE-C1-INH is a rare, potentially life-threatening condition usually associated with lymphoid malignancy or monoclonal gammopathy of uncertain significance. Angioedema attacks respond to treat- ment with icatibant or $\mathrm{C} 1-\mathrm{INH}$ concentrates, and lymphoma treatment may improve the control of AAE manifestation. According to our experiences, in some cases, C1-INH deficiency may resolve spontaneously.

\section{Acknowledgements}

Institute of Medical Biochemistry and Laboratory Diagnostics of the General University Hospital and of The First Faculty of Medicine of Charles University (Prague) is thanked for the analysis of C1q plasma levels in some of our patients, and Molecular Genetics Laboratory of the Center for Cardiovascular Surgery and Transplantation is thanked for genetic analysis of SERPING1 mutations. Institute of Biostatistics and Analyses, Ltd., is thanked for collection management and providing data from the Czech Republic Primary Immunodeficiency Database. The authors also thank Zuzana Strizova for language correction.

\section{Statement of Ethics}

This study was approved by the Ethics Committee for MultiCentric Clinical Trials of the University Hospital Motol (Reference No. EK-578/19), and all living patients gave written informed consent.

\section{Conflict of Interest Statement}

M. Sobotkova reports being a consultant and speaker for Takeda and receiving symposium sponsorship from CSL Behring and Takeda. R. Zachova reports receiving symposium sponsorship from CSL Behring and Takeda and served as an investigator for clinical trial sponsored by Pharming Group NV. R. Hakl reports receiving consultancy/speaker honoraria from CSL Behring, Shire, and Takeda Pharmaceutical Co., Ltd., and serving as a principal investigator for clinical trials sponsored by BioCryst Pharmaceuticals, Pharming Group NV, and KalVista Pharmaceuticals. P. Kuklinek reports being a consultant and speaker for Takeda and receiving symposium sponsorship from Takeda. P. Kralickova reports being a consultant and speaker for Takeda and CSL Behring and moreover receiving symposium sponsorship from them. I. Krcmova reports being a consultant and speaker for Takeda and receiving symposium sponsorship from Takeda. J. Hanzlikova reports being a consultant and speaker for Takeda and receiving symposium sponsoring from CSL Behring and Takeda. M. Vachova reports receiving symposium sponsorship from Takeda. J. Bartunkova has no conflicts of interest to declare.

\section{Funding Sources}

This study had no financial support. 


\section{Author Contributions}

Marta Sobotkova acquired, analyzed, and interpreted data and wrote the article. Roman Hakl, Pavel Kuklinek, Pavlina Kralickova, Irena Krcmova, Jana Hanzlikova, and Martina Vachova acquired and provided data, revised the article, and gave approval to the final version to be published. Pavlina Kralickova also helped with study design and data interpretation. Jirina Bartunkova supervised the project, revised the article, and also approved the final version to be published.

\section{References}

1 Cicardi M, Suffritti C, Perego F, Caccia S. Novelties in the diagnosis and treatment of angioedema. J Investig Allergol Clin Immunol. 2016;26(4):212-21.

2 Bork K, Staubach-Renz P, Hardt J. Angioedema due to acquired $\mathrm{C} 1$-inhibitor deficiency: spectrum and treatment with C1-inhibitor concentrate. Orphanet J Rare Dis. 2019 Mar; 14(1):65.

3 Gobert D, Paule R, Ponard D, Levy P, Frémeaux-Bacchi V, Bouillet $\mathrm{L}$, et al. A nationwide study of acquired C1-inhibitor deficiency in France: characteristics and treatment responses in 92 patients. Medicine. 2016;95:e4363.

4 Bygum A, Vestergaard H. Acquired angioedema: occurrence, clinical features and associated disorders in a Danish nationwide patient cohort. Int Arch Allergy Immunol. 2013 Jul;162(2):149-55.

5 Cicardi M, Aberer W, Banerji A, Bas M, Bernstein JA, Bork K, et al. Classification, diagnosis, and approach to treatment for angioedema: consensus report from the Hereditary Angioedema International Working Group. Allergy. 2014 May;69(5):602-16.
6 Maurer M, Magerl M, Ansotegui I, AygörenPürsün E, Betschel S, Bork K, et al. The international WAO/EAACI guideline for the management of hereditary angioedema: the 2017 revision and update. Allergy. 2018 Aug; 73(8):1575-96.

7 Cicardi M, Zanichelli A. Acquired angioedema. Allergy Asthma Clin Immunol. $2010 \mathrm{Jul}$ $28 ; 6(1): 14$

8 Up-to-date [Internet]. Saini S. Acquired C1 inhibitor deficiency: clinical manifestations, epidemiology, pathogenesis, and diagnosis. [cited 2020 May 26]. Available from: https:// www.uptodate.com/contents/acquired-c1inhibitor-deficiency-clinical-manifestationsepidemiology - pathogenesis - anddiagnosis? search $=$ acquired $\% 20 \mathrm{c} 1 \% 20$ inhibitor\%20deficiency\& source $=$ search_result\& selectedTitle $=1 \sim 36 \&$ usage_type $=$ default $\&$ display_rank=1.

9 Sbattella M, Zanichelli A, Ghia P, Gattei V, Suffritti C, Teatini T, et al. Splenic marginal zone lymphomas in acquired C1-inhibitor deficiency: clinical and molecular characterization. Med Oncol. 2018 Aug 2;35(9):118.

10 Zanichelli A, Azin GM, Wu MA, Suffritti C, Maggioni L, Caccia S, et al. Diagnosis, course, and management of angioedema in patients with acquired $\mathrm{C} 1$-inhibitor deficiency. J Allergy Clin Immunol Pract. 2017 Sep-Oct; 5(5):1307-13.
11 Up-to-date [Internet]. Saini S. Acquired C1 inhibitor deficiency: management and prognosis. [cited 2020 May 26]. Available from: https://www.uptodate.com/contents/acquiredc1-inhibitor-deficiency-management-andprognosis? search=acquired $\% 20 \mathrm{c} 1 \% 20$ inhibitor\%20deficiency\& source $=$ search_result\& selectedTitle $=2 \sim 36 \&$ usage_type $=$ default $\&$ display_rank $=2$.

12 Castelli R, Zanichelli A, Cicardi M, Cugno M. Acquired C1-inhibitor deficiency and lymphoproliferative disorders: a tight relationship. Crit Rev Oncol Hematol. 2013 Sep; 87(3):323-32.

13 Information from Czech statistical office [internet]. Pohyb obyvatelstva -rok 2018 [cited 2020 Jun 5]. Available from: https://www. czso.cz/csu/czso/cri/pohyb-obyvatelstvarok-2018.

14 Zanichelli A, Magerl M, Longhurst H, Fabien $\mathrm{V}$, Maurer M. Hereditary angioedema with $\mathrm{C} 1$ inhibitor deficiency: delay in diagnosis in Europe. Allergy Asthma Clin Immunol. 2013 Aug;9(1):29.

15 Christiansen SC, Davis DK, Castaldo AJ, Zuraw BL. Pediatric hereditary angioedema: onset, diagnostic delay, and disease severity. Clin Pediatr. 2016 Sep;55(10):935-42. 